\title{
EVALUATION OF A PERFORMANCE INDEX FOR MUNICIPAL WASTEWATER TREATMENT PLANTS USING MCDM - TOPSIS
}

\author{
Anaokar G. S. ${ }^{1 *}$, Khambete A. K. ${ }^{1}$, Christian R. A. ${ }^{1}$ \\ ${ }^{1}$ Civil Engineering Department, Sardar Vallabhbhai National Institute of Technology, Surat, Gujarat \\ 395007, India
}

(Received: April 2017 / Revised: January 2018 / Accepted: May 2018)

\begin{abstract}
Deciding which are the best performing wastewater treatment plants can be complicated, as their operations comprise different parameters which are either dependent or non-dependent on each other, and are important when deciding the type of treatment. The relative importance of these parameters in terms of weight indicates the priority assigned by decision-makers to the criteria when ranking the alternatives. These weights are calculated by statistical relativity and Saaty's nine point scale. The sensitivity of both of these approaches is analyzed. The performance of six municipal wastewater treatment plants is evaluated using the Multi-criteria Decision Making (MCDM) Technique for Order of Preference by Similarity to Ideal Solution (TOPSIS). Efficiency is monitored on the basis of nine wastewater characteristics and compared with the limits established by the Central Pollution Control Board of India. The analysis uses both qualitative and quantitative approaches, which result in differential rankings; accordingly, plants with maximum organic loading removal efficiency were found to be most efficient when weights were applied as per Saaty's scale. The study proposes a field base approach with regard to the suitability of the weight allocation method for respective utilization of the fuzzy approach in environmental monitoring systems.
\end{abstract}

Keywords: Fuzzy multi-criteria decision making; Performance index; Sensitivity; Standard deviation

\section{INTRODUCTION}

A typical wastewater treatment operation mainly deals with the removal of all forms of solids, foul-smelling gases and bacterial presence. The continuous operation of such plants is monitored through their inlet and outlet characteristics after every succeeding unit so that the performance of each unit can be evaluated. Performance evaluation of a wastewater treatment plant (WWTP) is difficult because of the fluctuations in inlet characteristics due to floating populations and changing lifestyles; seasonal variations, which may include the intrusion of storm water in monsoon seasons; temporal changes; and non-uniformity in the sampling and characterization process. The performance evaluation process mainly involves taking decisions on the basis of these characteristics as the criteria. Finding an optimal solution becomes complicated when the criteria are more numerous (Christian et al., 2008).

According to Han and Song (2011), the principles of a performance evaluation index system design mean that it must be scientific and applicable; hierarchical and comprehensive; operable and comparable; and evidence-based and verifiable (Han \& Song, 2011).

\footnotetext{
*Corresponding author's email: gsanaokar@gmail.com, Tel. +91-9422054584

Permalink/DOI: https://doi.org/10.14716/ijtech.v9i4.102
} 
Mechanically, the performance of wastewater treatment plants is evaluated on the basis of the influent and effluent characteristics (Mines et al., 2006; Kumar et al., 2010; Baghapour et al., 2013; Tripathi \& Singal, 2013). Efficiency can be calculated after every stage of treatment (Gallego et al., 2008; Han \& Song, 2011; Khambete, 2013; Khambete \& Christian, 2014). When multiple outcomes are governed by multiple input parameters, analysis with logical tools would be the best approach. In recent years, attempts have been made to evaluate performance using the fuzzy logic approach based on artificial neural networks, and multi-criteria decision making tools, amongst other approaches (Ráduly et al., 2007; Han \& Song, 2011; Nasr et al., 2012; Vítěz et al., 2012).

Mohammed (2006) and Alzboon and Al-Ananzeh (2008) evaluated efficiency on the basis of the removal of biological oxygen demand (BOD) at influent and discharge levels, which was found to be satisfactory (Mohammed, 2006). In 2008 Alzboon conducted characterization of wastewater, evaluating it in terms of measured Dissolved Oxygen (DO), Chemical Oxygen Demand (COD), BOD, solids and Ammonia Nitrogen $\left(\mathrm{NH}_{4}\right)$ in the influent and effluent wastewater from four selected plants in Jordan. The quality of the treated wastewater was matched with Jordanian standards (Alzboon \& Al-Ananzeh, 2008). Kumar et al. (2010) evaluated the performance of a sewage treatment plant operating by the biological treatment method. Mines et al. (2006) surveyed twenty-four WWTPs in Georgia and assessed their performance on the basis of influent and effluent Biochemical Oxygen Demand (BOD5), Total Suspended Solids (TSS), ammonia nitrogen $\left(\mathrm{NH}_{3}-\mathrm{N}\right)$, and Total Phosphorus (TP). Time series plots were generated to show wastewater treatment as a function of the type of treatment technology and temperature; (Mines et al., 2006). Sánchez et al. (2007) compared four plants using different technologies; plant efficiency (E) was evaluated after 19 months of monitoring inlet and outlet TSS, ammonia, $\mathrm{COD}$ and $\mathrm{BOD}_{5}$. The correlation between these parameters was studied and an empirical logarithmic relation was found from the experimental data (Sánchez et al., 2007). Gallego et al. (2008) divided WWTP in four sub-systems: pretreatment and primary treatment; secondary treatment; transport; and sludge use. Accordingly, a detailed assessment was carried out on the basis of electricity and chemical consumption, sludge and other waste generated in the WWTP, and the type of technologies used for secondary treatment (Gallego et al., 2008). Overall, the attempts to evaluate the performance of municipal wastewater treatment plants have neglected the seasonal variations in influent characteristics, the principle mechanisms of the plant, and the varying flow rates. These limitations have been overcome in recent studies by applying the fuzzy logic approach. This is a complex mathematical method that allows the solving of difficult simulated problems with many inputs and output variables (Zadeh, 1988; Novak \& Lehmke, 2006; Malekinezhad, 2014).

Sudasinghe et al. (2011) carried out performance evaluation on the basis of 109 performance criteria using clusterization. The combined scores for performance were described using linguistic variables. Overall performance was ascertained by proportioning the number of better performing criteria to the total number of criteria tested (Sudasinghe et al., 2011). Ráduly et al. (2007) evaluated the performance of wastewater treatment plants using the artificial neural network (ANN) approach; an influent disturbance generator was combined with a mechanistic WWTP model, which helped to develop a limited sequence of training data collected over four months. An ANN model, calibrated using the available WWTP data and influent time series over twenty years, was generated. Results were obtained at an acceptable level, in accordance with the urban context, with errors of less than $10 \%$ (Ráduly et al., 2007). Nasr et al. (2012) also evaluated performance using an artificial neural network. His study provided results with an $R$ value of 0.90 , indicating an acceptable correlation between the observed and predicted output variables (Nasr et al., 2012). When the probabilities of the outcomes are unknown, decisions are made under uncertainties, which is the prime domain of fuzzy decision making. Fuzzy multi-criteria 
decision making is concerned with structuring and solving decisions and planning problems involving multiple criteria. The characterization of wastewater involves different parameters, which are dependent or non-dependent on each other; but are more important when deciding treatment. This makes it difficult to make decisions on optimally performing treatment plants.

Multi-criteria decision making (MCDM) is a discipline of operational research, in which multiple criteria are involved in decision-making environments in order to reach optimal solutions. The Technique for Order of Preference by Similarity to Ideal Solution (TOPSIS) is a decision-making tool which is based on calculating the geometric distance between each alternative and ideal alternative within each criterion (Wang \& Elhag, 2006; Shi et al., 2010.; Antucheviciene et al., 2010; Nezhad et al., 2015) Wastewater treatment plant operations are subject to different criteria and as they should be compared with discharge standards, this indicates that evaluation with TOPSIS is feasible. Fuzzy TOPSIS is a method of compensatory aggregation. This approach allows affairs within criteria to nullify a poor result of one criterion with a good result of another. This provides a more realistic form of modelling than non-compensatory methods, which include or exclude alternative solutions based on strict limits (Zavadskas et al., 2006). Weight or relative importance of a criterion indicates the priority which a decision-maker assigns to it while ranking the alternatives (Loucks et al., 2005).

In this study, performance evaluation of municipal wastewater treatment using fuzzy multicriteria decision making has been conducted on six major treatment plants in India. Although several evaluation approaches are available, they are tend to be based on insufficient assessment carried out by referring inadequate datasets; neglecting the overall adverse effects on the environment (Puig et al., 2008; Puig et al., 2010). In the fuzzy approach, the relative importance of the evaluation criteria need to be adopted by considering all the dependent parameters. The weights of the variables could be allotted either by statistical correlation or by considering expert opinion. The statistical approach is a merely mechanical one, with the essence of mathematical relativity, without considering the realistic loading removal trends which occur due to the seasonal variations in wastewater flow and the treatment mechanisms at the wastewater treatment plants. When weights were allocated on the basis of Saaty's scale, the results found were acceptable, as they were the combination of qualitative and quantitative evaluations of the wastewater.

\section{METHODS}

The type of treatment adopted in MWWTP is dependent on inlet waste water characteristics such as $\mathrm{pH}$, temperature, solids in dissolved and suspended states (TDS and TSS), chlorides, Biological Oxygen Demand (BOD) and Chemical Oxygen Demand (COD).

The study area was specially selected due to certain parameters, such as the geometric growth of the population and infrastructure development in recent decades; inclusion within the smart city corridor; the need for efficiency assessment by last so many years; and the need for optimization in wastewater treatment operation with reference to power consumption and operational costs. Six WWTPs with almost equal capacities were selected. The sampling for all six WWTPs was carried out over a period of twelve months. After every treatment step, samples were collected, and each WWTP was sampled three times during the evaluation period. The average values were considered for further decision making processes. The performance evaluation of WWTPs was carried out based on the following criteria: temperature, Total Dissolved Solids (TDS), Suspended Solids (SS), Biological and Chemical Oxygen Demand (BOD and COD), pH and chlorides. Samples were preserved at $4^{\circ} \mathrm{C}$ when transporting them to the laboratory. They were immediately analyzed for Chemical Oxygen Demand (COD), Biochemical Oxygen Demand $\left(\mathrm{BOD}_{5}\right), \mathrm{pH}$ and turbidity, with all the analyses carried out following the Standard Methods 
(American Public Health Association - APHA, 1998). Detailed characterization of the wastewater samples is summarized in Table 1, with average values of three sampling periods.

Normalization is the practice of eliminating redundant data from crisp data in order to improve data integrity and scalability. In other ways, normalization helps to convert all fuzzified data into the range ' 0 ' to ' 1 '. This also helps to equalize the units of all the characterization parameters. The crisp data, tabulated in Table 1, is normalized with reference to the standard limits laid out by CPCB to attain the maximum possible membership grade with reference to the CPCB limits. In this case, normalization was carried out by converting the raw scores, which were originally measured in situ, into what is often referred to as the objective scale, ones that range from 0 (the minimum) to 1 (the maximum). The crisp data in the form of the daily characteristics of the wastewater inlets and outlets was used. These are the usual steps adopted in the fuzzy TOPSIS decision making process. In further steps, weights are assigned to the dependent variables and accordingly the fuzzified data is analyzed. A comparison between the sets of alternatives was carried out by identifying weights for each criterion. The scores obtained for each criterion were normalized to maintain uniformity with reference to the units. The geometric distance was calculated between each alternative and the ideal alternative, which was considered as the best score in each criterion (Abo-Sinna \& Amer, 2005; Wang \& Elhag, 2006). In ideal conditions, an optimal solution is replaced by the set of non-dominated solutions. At the same time, such a solution never moves away from the optimal solution without sacrificing at least one criterion with reference to the other solutions. This allows the decision maker to choose a solution from the non-dominated set (Dursun, 2016; Opricovic \& Tzeng, 2003).

Table 1 Characteristics of the treated wastewater - average values and limits set by the Central Pollution Control Board of India

\begin{tabular}{lcccccccc}
\hline \multirow{2}{*}{ Attributes } & \multicolumn{8}{c}{ Criteria } \\
\cline { 2 - 9 } & Temp & TDS & SS & BOD & COD & Nitrogen & pH & Cl \\
\hline Limits & 40 & 2100 & 20 & 10 & 50 & 10 & $6.5-9.0$ & 600 \\
WWTP $_{1}$ & 31.8 & 654 & 13 & 9.45 & 42 & 23.5 & 7.15 & 165.1 \\
WWTP $_{2}$ & 30.6 & 568 & 10.75 & 11.2 & 32.5 & 24 & 7.57 & 117.5 \\
WWTP $_{3}$ & 30.45 & 224.9 & 12.5 & 10.1 & 52 & 26 & 7.47 & 211 \\
WWTP $_{4}$ & 29.8 & 760.5 & 14 & 11.4 & 25.9 & 27.5 & 7.38 & 110 \\
WWTP $_{5}$ & 30.65 & 651.8 & 19.5 & 9 & 40.25 & 28 & 7.46 & 175.5 \\
WWTP $_{6}$ & 29.6 & 462 & 14.5 & 11.4 & 51.5 & 26 & 7.46 & 213.2 \\
\hline
\end{tabular}

For weight allocation two approaches were adopted. In the first approach, a statistical method of regression and correlation was attempted. The analysis was carried out using Microsoft Office Excel for the 335 sets of data. A correlation coefficient provides the range up to which two variables in the data set tend to change together. Pearson correlation was formulated; this calculates the linear relationship between two variables. A relationship is linear when a change in one variable is associated with a proportional change in another. If two independent variables are highly correlated, only one may end up in the model, even though either may be important. As the procedure suits many models, it is possible to select any parameter that fits the data well, which is down to chance alone. The correlations found are tabulated in Table 2. Standard deviation is a measure to quantify the level of variation or dispersion of a dataset. It is the most common measure of dispersion, or how spread out the data are from the mean. While range estimates the spread of the data by subtracting the minimum value from the maximum one, standard deviation roughly estimates the "average" distance of the individual observations from the mean. 
Table 2 Correlation analysis for wastewater characteristics

\begin{tabular}{lcccccccr}
\hline & Temp. & TDS & SS & COD & Nitrogen & Cl- & pH & BOD \\
\hline Temp. & 1.000 & & & & & & & \\
TDS & -0.016 & 1.000 & & & & & & \\
SS & 0.316 & -0.010 & 1.000 & & & & & \\
COD & 0.168 & -0.035 & 0.854 & 1.000 & & & & \\
Nitrogen & 0.351 & -0.240 & 0.308 & 0.271 & 1.000 & & & \\
Cl $^{-}$ & -0.201 & 0.545 & 0.011 & -0.008 & -0.188 & 1.000 & & \\
pH & 0.081 & 0.110 & 0.400 & 0.393 & 0.133 & 0.154 & 1.000 & \\
BOD & 0.353 & -0.089 & 0.855 & 0.925 & 0.353 & -0.062 & 0.443 & 1.000 \\
\hline
\end{tabular}

Here, the mean of the data was subtracted and divided by standard deviation. The standard deviation " $\sigma$ " was calculated using Equation 1, which gave the data dispersion.

$$
\sigma=\sqrt{\sum_{i=1}^{N} \frac{\left(x_{1}-\bar{x}\right)^{2}}{N-1}}
$$

where $x_{1}, x_{2}, \ldots . x_{n}$ are the observed values of the sample items; $x_{1}$ is the mean value of these observations; and $N$ is the number of observations in the sample. Standard deviation can be used as a preliminary benchmark for estimating the overall variation of a process. This process made all datasets unit less. The above statistical operation was utilized to check for the possibility of interrelationships between the wastewater characteristics. In the next steps, clustering depending on physical, organic and inorganic characteristics was obtained. This was essential to identify the importance of each parameter reflecting towards overall characteristics. A matrix was constructed indicating pair-wise importance over each other. In the first cluster of physical parameters, the importance of TDS over temperature was considered that of 3 times more. Similarly for the others. For the mathematical approach of assigning weights, a correlation analysis was carried out, considering the consistency ratio (CR) and consistency index (CI). A CR value that is lower than 0.10 is generally acceptable; if not, the pair-wise comparison needs to be revised (Abid \& Bahloul, 2011).

Thus for the physical cluster:

\begin{tabular}{l|ccc} 
& Temp & TDS & SS \\
Temp & 1.00 & 0.33 & 0.17 \\
TDS & 3.00 & 1.00 & 0.33 \\
SS & 6.00 & 3.00 & 1.00
\end{tabular}

Check for Consistency Ratio (C/R):

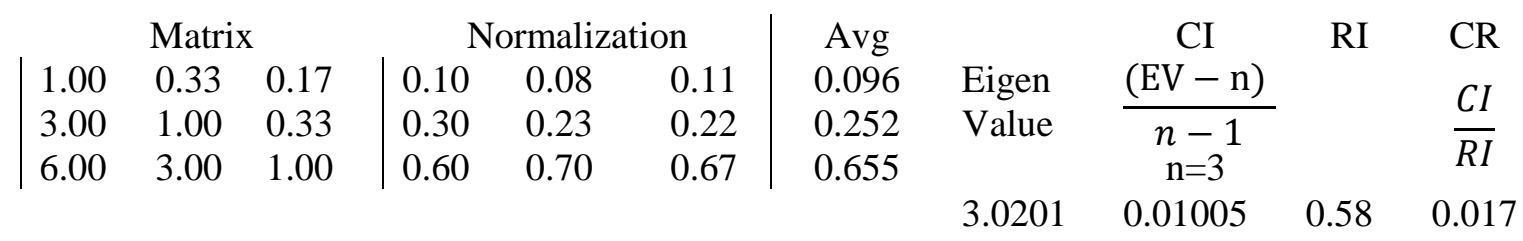

As $\mathrm{CR}<0.15$, the weights allocated are valid.

Similarly, for the organic and inorganic clusters:

\begin{tabular}{c|ccc|}
\multicolumn{1}{c}{$\mathrm{pH}$} & Chlorides & Nitrogen \\
$\mathrm{pH}$ & 1 & 1 & 3 \\
Chlorides & 1 & 1 & 3 \\
Nitrogen & $1 / 3$ & $1 / 3$ & 1
\end{tabular}


Check for Consistency Ratio (C/R):

\begin{tabular}{|c|c|c|c|c|c|c|c|c|c|c|}
\hline \multicolumn{3}{|c|}{ Matrix } & \multicolumn{3}{|c|}{ Normalization } & Avg & Eigen & CI & RI & $\mathrm{CR}$ \\
\hline 1.00 & 0.33 & 0.17 & 0.43 & 0.43 & 0.43 & 0.43 & Value & $(E V-n)$ & & 保 \\
\hline 3.00 & 1.00 & 0.33 & 0.43 & 0.43 & 0.43 & 0.43 & & $n-1$ & & $R$ \\
\hline 6.00 & 3.00 & 1.00 & 0.14 & 0.14 & 0.14 & 0.14 & & $n=3$ & & \\
\hline & & & & & & & 2.71 & 0 & 0.58 & \\
\hline
\end{tabular}

$\mathrm{CI}=0$, due to identical row.

Weight Allocation for the inorganic cluster:

\begin{tabular}{l|cc} 
BOD & COD \\
COD & 1 & 5 \\
$1 / 5$ & 1
\end{tabular} \mid

\begin{tabular}{cc|cc|c}
\multicolumn{3}{c}{ Matrix } & \multicolumn{3}{c}{ Normalization } & Avg \\
1 & 5 & 0.84 & 0.84 & 0.84 \\
0.2 & 1 & 0.16 & 0.16 & 0.16
\end{tabular}

In another approach to assigning weights to each parameter, the nine point scale devised by Saaty was adopted (Machacha \& Bhattacharya, 2000; Paralikas \& Lygeros, 2005; Zhao et al., 2008; Tsaura et al. 2002; Wang \& Wang, 2010). This scale is summarized in Table 3 (Saaty 2008). Opinions of experts from different fields such as academia and the environment are considered when decision makers assign weights (Alvarez \& Skarmeta, 2004). The fuzzy variables themselves are adjectives that modify the variable; these are called linguistic variables. These variables provide better buffers to come closer to optimum decisions.

Table 3 Saaty's nine point scale for pair-wise comparison

\begin{tabular}{cl}
\hline Intensity of Importance & \\
\hline 1 & Equal importance \\
3 & Weak importance of one over another \\
5 & Strong importance \\
7 & Demonstrated importance \\
$2,4,6,8$ & Absolute importance \\
Intermediate values \\
Reciprocals of the above & $\begin{array}{l}\text { If activity i has one of the above numbers assigned to it when compared } \\
\text { with activity j, then j has the reciprocal value when compared with i }\end{array}$ \\
$1.1-1.9$ & When elements are close and nearly indistinguishable \\
\hline
\end{tabular}

To define the relative weights, linguistic variables were defined and are tabulated in Table 3 . The relative levels of importance are described as highly significant, significant, of average significance, low significance, and negatively significant. The criteria are thus evaluated on the basis of these weights. Environmental experts have allotted the weights to the predefined parameters, as shown in Table 4.

Table 4 Linguistic variables with corresponding fuzzy numbers

\begin{tabular}{lc}
\hline \multicolumn{1}{c}{ Linguistic Variables } & Fuzzy Number \\
\hline Highly Significant - HS & $(0.7,0.8,0.9,1.0)$ \\
Significant $-\mathrm{S}$ & $(0.5,0.6,0.7,0.8)$ \\
Average Significance - AvS & $(0.3,0.4,0.5,0.6)$ \\
Low Significance - LS & $(0.1,0.2,0.3,0.4)$ \\
Negatively Significant - NS & $(0.0,0.0,0.1,0.2)$ \\
\hline
\end{tabular}


Referring to Tables 4 and 5, a fuzzy decision matrix was constructed, which provides the basic framework for the collection and organization of information. A decision matrix contains the data for comparing the decision alternatives in accordance with the linguistic variables and corresponding fuzzy numbers.

Table 5 Linguistic variables with corresponding fuzzy number

\begin{tabular}{lcccccc}
\hline \multirow{2}{*}{ Temp } & EE1 & EE2 & EE3 & EE4 & EE5 & EE6 \\
\cline { 2 - 6 } & LS & LS & AvS & AvS & AvS & Avs \\
\hline TDS & S & HS & S & HS & S & AvS \\
SS & S & S & AvS & AvS & HS & HS \\
BOD & HS & HS & HS & S & S & LS \\
COD & HS & S & HS & AvS & S & HS \\
Nitrogen & LS & AvS & S & AvS & S & LS \\
pH & S & AvS & AvS & AvS & S & AvS \\
Cl & S & AvS & AvS & S & LS & AvS \\
\hline
\end{tabular}

In this way, an expert opinion is formulated so as to relate each criterion to the corresponding fuzzy number. Averaging and aggregation was carried for each matrix parameter shown in the matrix. The problem of discrete multiple criteria evaluation was formulated by considering sets of alternatives and set of criteria. After isolation and defuzzification a normalized weight for each criterion was calculated. Table 6 shows the normalized weights for corresponding criteria, indicating the importance of each parameter in accordance with expert opinion.

Table 6 Isolated and defuzzified weights with normalization

\begin{tabular}{lcccccc}
\hline \multicolumn{5}{c}{ Average Fuzzy Numbers } & Defuzzified value & Normalized Weight \\
\hline Temp & 0.23 & 0.33 & 0.43 & 0.53 & 0.455 & 0.0956 \\
TDS & 0.53 & 0.63 & 0.73 & 0.83 & 0.68 & 0.1429 \\
SS & 0.50 & 0.60 & 0.70 & 0.80 & 0.65 & 0.1366 \\
BOD & 0.53 & 0.63 & 0.73 & 0.83 & 0.68 & 0.1429 \\
COD & 0.56 & 0.66 & 0.76 & 0.86 & 0.71 & 0.1492 \\
$\mathrm{~N}_{2}$ & 0.30 & 0.40 & 0.50 & 0.60 & 0.45 & 0.0945 \\
pH & 0.41 & 0.46 & 0.56 & 0.66 & 0.5225 & 0.1098 \\
$\mathrm{Cl}$ & 0.33 & 0.40 & 0.53 & 0.63 & 0.4725 & 0.0993 \\
\hline
\end{tabular}

Table 7 Normalized weights obtained from the statistical approach and Saaty's nine point scale

\begin{tabular}{lcc}
\hline \multirow{2}{*}{ Parameter } & \multicolumn{2}{c}{ Normalized Weight } \\
\cline { 2 - 3 } & By statistical approach & By Saaty's nine point scale \\
\hline Temp & 0.097 & 0.096 \\
TDS & 0.143 & 0.252 \\
SS & 0.137 & 0.655 \\
BOD & 0.143 & 0.430 \\
COD & 0.143 & 0.430 \\
Nitrogen & 0.094 & 0.140 \\
pH & 0.127 & 0.840 \\
Cl & 0.100 & 0.160 \\
\hline
\end{tabular}

In Table 7, weights are calculated by statistical analysis and those on Saaty's nine-point scale are summarized. In Equation 1, these weights are allotted to the parameters in order to fuzzify the crisp data. 


$$
T=\left(t_{i j}\right) m \times n=\left(w_{j} r_{i j}\right) m \times n, \quad i=1,2,3 \ldots \ldots m
$$

TOPSIS is based on the concept that the chosen alternative should have the shortest geometric distance from the positive ideal solution, and the longest geometric distance from the negative ideal solution. Equations 3 and 4 provide these corresponding distances from the ideal solutions.

It is possible to analyze the best and worst ideal solutions. Using Equations 3 and 4, the corresponding positive ideal, i.e. the best and negative ideal, the worst solution, can be obtained.

$$
\begin{aligned}
& \mathrm{A}_{\mathrm{w}}=\left\{\left(\max \left(\mathrm{t}_{\mathrm{ij}}: \mathrm{i}=1,2, ., \mathrm{m}: \mathrm{j} \in \mathrm{J}_{-}\right),\left(\min \left(\mathrm{t}_{\mathrm{ij}}: \mathrm{i}=1,2, ., \mathrm{m}\right): \mathrm{j} \in \mathrm{J}+\right)\right\}=\mathrm{t}_{\mathrm{wj}}: \mathrm{j}=1,2, \ldots \mathrm{n}\right\} \\
& \mathrm{A}_{\mathrm{b}}=\left\{\left(\min \left(\mathrm{t}_{\mathrm{ij}}: \mathrm{i}=1,2, ., \mathrm{m}: \mathrm{j} \in \mathrm{J}_{-}\right),\left(\max \left(\mathrm{t}_{\mathrm{ij}}: \mathrm{i}=1,2, ., \mathrm{m}\right): \mathrm{j} \in \mathrm{J}+\right)\right\}=\mathrm{t}_{\mathrm{bj}}: \mathrm{j}=1,2, \ldots \mathrm{n}\right\}
\end{aligned}
$$

Considering these positive and negative ideals as datum values, a scale is developed which indicates the measure of separation of each alternative solution $\left(t_{i j}\right)$. The best option can be obtained by considering the positive ideal solutions; the worst one by considering the negative ideal solutions. Using the measure of separation, the best and worst options can be calculated using Equations 5 and 6 (Mahmoodzadeh et al., 2007).

$$
\begin{aligned}
& \left.S_{i b}=\sqrt{\sum_{j=1}^{n}\left(t_{i j}\right.}-t_{w j}\right)^{2}, i=1,2, \ldots \ldots, m \\
& \left.S_{i w}=\sqrt{\sum_{j=1}^{n}\left(t_{i j}\right.}-t_{b j}\right)^{2}, i=1,2, \ldots \ldots, m
\end{aligned}
$$

where $S_{\text {ib }}$ gives the best ideal solution and $S_{\text {iw }}$ gives the worst ideal solution. The concept of best and worst ideal solution is the measure of separation for the best and worst options.

The ranking process was achieved using the closeness coefficient, which is the number close to the best option. This coefficient can be obtained using Equation 7. In the case of the performance evaluation of WWTP, it can be interpreted that the lower the rank, the lower the level of pollution and hence the more efficient the treatment process. This process of ranking can be achieved by using:

$$
\mathrm{R}_{\mathrm{iw}}=\left[\mathrm{S}_{\mathrm{iw}} /\left(\mathrm{S}_{\mathrm{iw}}+\mathrm{S}_{\mathrm{ib}}\right)\right] \leq \mathrm{I}_{\mathrm{iw}} \leq 1, \mathrm{i}=1,2, \ldots \ldots \mathrm{m} .
$$

Worst score which indicates, rank $\mathrm{R}_{\mathrm{iw}}$; is the proportion of the best ideal solution to the worst ideal solution scale, with reference to the worst ideal solution. This will give an idea for further ranking procedures. Using Equation 7, the ranking was calculated, as shown in Table 8.

\section{RESULTS AND DISCUSSION}

Performance evaluation of wastewater treatment plants can be a complex procedure, as numerous evaluation criteria exist, which differ in their multiple parameters. A key concept of TOPSIS is to measure each alternative's distance from the positive and negative ideal solutions separately. The best alternative should be very close to the ideal solution and furthest from the negative one. In this experimental work, the fuzzy decision analysis tool has been proven to be a suitable approach.

In the overall assessment process, applied weights play a key role. These provide tuning in the decision making process. Weights indicate the importance of each criterion in context to output. In the statistical approach, weights are calculated by considering the correlations and regressions of individual input parameters with each other. The results show that $\mathrm{WWTP}_{6}$ was ranked 1, but looking at its BOD and COD handling rate, practically all the results are somehow discrepant. The variation in weight for individual criteria is shown in Table 7. 
There are a few parameters which carry the same weight. When calculated statistically, this fact is based on field database; whereas in the other approach it is based entirely on expert opinion and hence is found to be true in practice. The low weight for an important parameter such as $\mathrm{pH}$ in the statistical approach is only due to the uncertain field data obtained due to seasonal variation and dilution. This shows that it is better to adopt weights taking into consideration the practical scenario and expert judgments. Satty's nine-point scale provides a better judgmental base to that of the experts and helps to simplify the complex process of pair-wise comparison. In this particular approach, it is convenient to express the relative importance. Considering all these factors and concerning the approach to applying weights to the criteria, the ranking was obtained and is shown in Table 8.

In Table 8, the ranking is calculated with $\mathrm{WWTP}_{2}$ ranked 1 , with the lowest score of 0.455 . This lowest score indicates greatest efficiency in accordance with qualitative performance. The best ideal solution will be close to the standard discharge limit, whereas the worst ideal solution will away from this limit. This indicates that the best solution will achieve the lowest score, and vice versa.

Table 8 WWTP ranking

\begin{tabular}{ccc}
\hline & \multicolumn{2}{c}{ Rank } \\
\cline { 2 - 3 } Alternative & $\begin{array}{c}\text { With weights by statistical } \\
\text { approach }\end{array}$ & $\begin{array}{c}\text { With weights by fuzzy } \\
\text { decision matrix }\end{array}$ \\
\hline WWTP $_{1}$ & 4 & 2 \\
WWTP $_{2}$ & 3 & 1 \\
WWTP $_{3}$ & 2 & 4 \\
WWTP $_{4}$ & 6 & 6 \\
WWTP $_{5}$ & 5 & 5 \\
WWTP $_{6}$ & 1 & 3 \\
\hline
\end{tabular}

BOD, COD, TDS and SS are the important characteristics which indicate the pollution strength of the wastewater (Al-Ali et al., 2011; Central Pollution Control Board, 2010). The quality of wastewater is mainly identified by monitoring these parameters. The performance of WWTP 2 was also found to be better using this kind of analysis. Sensitivity in the decision making process depends on the ranking system. Use of MCDM in different environmental activities promotes resource optimization, cost reduction, and better control over the performance of the activities (Ghatak \& Mahanta, 2017). Applying TOPSIS to the performance evaluation process confirms that $\mathrm{WWTP}_{2}$ has scored low, indicating the best performance. In the statistical approach method, $\mathrm{WWTP}_{2}$ received the rank of 3 . This is due to the quantitative evaluation carried out in the statistical method of assessment, in which the site conditions are absolute, and the evaluation is carried out according to the mathematical correlation existing between the dependent variables (Gunaseelan, 2007; Schievano et al., 2009; Antucheviciene et al., 2010; Abhishek \& Khambete., 2013). In this analysis $\mathrm{WWTP}_{6}$ was ranked 1.

\section{CONCLUSION}

In the case of municipal wastewater treatment plants, the activated sludge process and extended aeration are the most commonly adopted principle mechanisms. In such circumstances, it is difficult to rank the plants, as their capacity and working approaches are different. The conventional input-output based efficiency audit fails due to uncertainty. The statistical approach to efficiency calculation is entirely qualitative, whereas the fuzzy approach provides qualitative as well as quantitative evaluation. The relative importance of each parameter is expressed in terms of weight. Application of weights to the criteria needs to be governed realistically. Thus when 
weights were applied mechanically by means of a mathematical tool, it was found that apart from typical performance indicators such as BOD and COD, the results were unacceptable and contradicted the field conditions. In the other approach, in which the weights were applied on the basis of Saaty's nine-point scale, the rankings were found to be realistic and matched their BOD and COD removal efficiency.

Consequently, $\mathrm{WWTP}_{2}$, with a score of 0.455 , was ranked 1, indicating the highest efficiency, whereas $\mathrm{WWTP}_{4}$, with a score of 0.649 , was ranked 6 when assessed on the basis of CPCB limits. The statistical approach is acceptable in terms of having less calculus and limited constraints. Certain parameters, such as infrastructure cost, land investment, power consumption and maintenance, could be applied at the end of the decision process.

\section{REFERENCES}

Abhishek, S., Khambete, A., 2013. Statistical Analysis to Identify the Main Parameters to the Wastewater Quality Index of CETP: A Case Study at Vapi, Gujarat, India. Journal of Environmental Research and Development, Volume 7(3), pp. 1294-1304

Abid, F., Bahloul, S., 2011. Selected MENA Countries' Attractiveness to G7 Investors. Economic Modelling, Volume 28(5), pp. 2197-2207

Abo-Sinna, M.A., Amer, A., 2005. Extensions of TOPSIS for Multi-objective Large-scale Nonlinear Programming Problems. Applied Mathematics and Computation, Volume 162(1), pp. 243-256

Alali, M., Abdulla, A.I., Mohammad, A.M., 2011. Estimating and Modelling the Interrelationships between Physicochemical Pollutants of Samara Drug Factory Wastewater. European Journal of Scientific Research, Volume 61(2), pp. 1450-216

Alvarez, D.S., Skarmeta, A.F.G., 2004. A Fuzzy Language. Fuzzy Sets and Systems, Volume 141(3), pp. 335-390

Alzboon, K.K., Al-Ananzeh, N, M., 2008. Performance of Wastewater Treatment Plants in Jordan and Suitability for Reuse. African Journal of Biotechnology, Volume 7(15), pp. 2621-2629

Antucheviciene, J., Zavadskas, E.K., Zakarevicius, A., 2010. Ranking of Construction Management Alternatives Considering Criteria Interrelations. Modern Building Materials, Structures and Techniques, Volume 1(1), pp. 351-355

Baghapour, M.A., Nasseri, S., Djahed, B., 2013. Evaluation of Shiraz Wastewater Treatment Plant Effluent Quality for Agricultural Irrigation by Canadian Water Quality Index (CWQI). Iranian Journal of Environmental Health Science \& Engineering, Volume 10(1):27, pp. 19

Central Pollution Control Board, 2010. 6.1 Performance Monitoring of Sewage Treatment Plants in Haryana and Delhi; 6.2 Performance Monitoring of Oxidation Ponds based STPs under NRCD Project; 6.3 Performance Monitoring of Sewage Treatment Plants in Bangalore and Vijaywada. Parivesh, 1(1), pp. 90-95

Christian, R.A., Lad, R.K., Deshpande, A.W., Desai, N.G., 2008. Fuzzy MCDM Approach for Addressing Composite Index of Water and Air Pollution Potential of Industries. International Journal of Digital Content Technology and Its Application, Volume 2(2), pp. 64-71

Dursun, M., 2016. Fuzzy MCDM Approach to Evaluate Wastewater Treatment Alternatives. Engineering Letters, Volume 24(2), pp. 231-236

Gallego, A., Hospido, A., Moreira, M.T., Feijoo, G., 2008. Environmental Performance of Wastewater Treatment Plants for Small Populations. Resources, Conservation and Recycling, Volume 52(6), pp. 931-940 
Ghatak, M., Pinakeswar, P., 2017. Kinetic Model Development for Biogas Production from Lignocellulosic Biomass. International Journal of Technology, Volume 8(4), pp. 673-680

Gunaseelan, V.N., 2007. Regression Models of Ultimate Methane Yields of Fruits and Vegetable Solid Wastes, Sorghum and Napiergrass on Chemical Composition. Bioresource Technology, Volume 98(6), pp. 1270-1277

Han, D., Song, G., 2011. Evaluation on the Performace of Urban Domestic Sewage Treatment Plants in China. IEEE China Development Report

Khambete, A., Christian, R.A., 2014. Ranking Sewage Treatment Plants with the Application of Fuzzy Composite Programming. International Journal of Scientific Engineering and Technology, Volume 3(2), pp. 116-120

Kumar, K.S., Kumar, P.S., Babu, M. JR., 2010. Performance Evaluation of Waste Water Treatment Plant. International Journal of Engineering Science and Technology, Volume 2(12), pp. 7785-7796

Loucks, D.P., Van Beek, E., 2005. Water Resources Systems Planning and Management-An Introduction to Methods, Models and Applications. Springer, pp. 135-144

Machacha, L.L., Bhattacharya, P., 2000. A Fuzzy-logic-based Approach to Project Selection. IEEE Transactions on Engineering Management, Volume 47(1), pp. 65-73

Mahmoodzadeh, S., Shahrabi, J., Zaeri, M.S., Pariazar, M., 2007. Project Selection by using Fuzzy AHP and TOPSIS Technique. International Journal of Human and Social Sciences, Volume 1(3), pp. 135-140

Malekinezhad, H., 2014. Regionalization Approach for Modeling of Monthly Evaporation based on Cluster Analysis. Natural Resources and Conservation, Volume 2(2), pp. 25-32

Mines, R.O., Lackey, L.W., Behrend, G.R., 2006. Performance Assessment of Major Wastewater Treatment Plants (WWTPs) in the State of Georgia. Journal of Environmental Science and Health, Volume 41(10), pp. 2175-2198

Mohammed, B., 2006. Design and Performance Evaluation of a Wastewater Treatment Unit. Alexandria Engineering Journal, Volume 9(3), pp. 193-1998

Nasr, M.S., Moustafa, M.A.E., Seif, H.A.E., El Kobrosy, G., 2012. Application of Artificial Neural Network (ANN) for the Prediction of EL-AGAMY Wastewater Treatment Plant Performance-EGYPT. Alexandria Engineering Journal, Volume 51(1), pp. 37-43

Nezhad, M.F., Mehrdadi. N., Torabian, A., 2015. Definition of a New Domestic Effluent Quality Index using TOPSIS Decision Making Tool. Canadian Journal of Pure and Applied Sciences, Volume 9(2), pp. 3467-3472

Novak, V., Lehmke, S., 2006. Logical Structure of Fuzzy IF-THEN Rules. Fuzzy Sets and Systems, Volume 157(15), pp. 2003-2029

Opricovic, S., Tzeng, G.-H., 2003. Defuzzification within a Multicriteria Decision Model. International Journal of Uncertainty, Fuzziness and Knowledge-Based Systems, Volume 11(5), pp. 635-652

Paralikas, A.N., Lygeros, A.I., 2005. A Multi-criteria and Fuzzy Logic Based Methodology for the Relative Ranking of the Fire Hazard of Chemical Substances and Installations. Process Safety and Environmental Protection, Volume 83(2), pp. 122-134

Puig, S., van Loosdrecht, M.C.M., Colprim, J., Meijer, S.C.F., 2008. Data Evaluation of Fullscale Wastewater Treatment Plants by Mass Balance. Water Research. Volume 42(18), pp. 4645-4655

Puig, S., van Loosdrecht, M.C.M., Flameling, A.G., Colprim, J, Meijer, S.C.F., 2010. The Effect of Primary Sedimentation on Full-scale WWTP Nutrient Removal Performance. Water Research, Volume 44(11), pp. 3375-3384

Ráduly, B., Gernaey, k.V., Capodaglio, A.G., Mikkelsen, P.S., Henze, M., 2007. Artificial Neural Networks for Rapid WWTP Performance Evaluation: Methodology and Case Study. Environmental Modelling \& Software, Volume 22(8), pp. 1208-1216 
Saaty, T.L., 2008. Decision Making with the Analytic Hierarchy Process. International Journal of Services Sciences, Volume 1(1), pp. 83-84

Sánchez, E., Colmenarejo, M.F., Vicente, J., Rubio, A., Garcia, M.G., Travieso, L., Borja, R., 2007. Use of the Water Quality Index and Dissolved Oxygen Deficit as Simple Indicators of Watersheds Pollution. Ecological Indicators, Volume 7(2), pp. 315-328

Schievano, A., Scaglia, B., D’Imporzano, G., Magalutti, L., Gozzi, A., Adani, F., 2009. Prediction of Biogas Potentials using Quick Laboratory Analyses: Upgrading Previous Models for Application to Heterogeneous Organic Matrices. Bioresource Technology, Volume 100(23), pp. 5777-5782

Shi, Y., Kou, G., Li, Y., Wang, G., Peng, Y., Shi, Y., 2010. FMCDM: A Fuzzy Multi-criteria Decision-making Hybrid Approach to Evaluate the Damage Level of Typhoon. Integration of Fuzzy AHP and Fuzzy TOPSIS. In: The $3^{\text {rd }}$ International Conference on Information Sciences and Interaction Sciences

Sudasinghe, M.I., Galagedara, L.W., Gunawardena, E.R.N., 2011. Performance Evaluation of Selected Sewerage Treatment Plants in Sri Lanka. Tropical Agricultural Research, Volume 22(2), pp. 154-164

Tripathi, M., Singal, S.K., 2013. Performance Evaluation of Sewage Treatment Plants in Lucknow City. Hydro Nepal, Volume (12), pp. 80-86

Tsaur, S.H., Chang, T.Y., Yen, C.H., 2002. The Evaluation of Airline Service Quality by Fuzzy MCDM. Tourism Management, Volume 23(2), pp. 107-115

Vítěz, T., Ševčíková, J., Oppeltová, P., 2012. Evaluation of the Efficiency of Selected Wastewater Treatment Plant. Acta Universitatis. Agriculturae et Silviculturae Mendelianae Brunensis, Volume 60(1), pp.173-180

Wang, M., Wang, L., 2010. Fuzzy Weight' s Calculation Method. In: The $6^{\text {th }}$ International Conference on Advanced Information Management and Service (IMS)

Wang, Y.M., Elhag, T.M.S., 2006. Fuzzy TOPSIS Method based on Alpha Level Sets with an Application to Bridge Risk Assessment. Expert Systems with Applications, Volume 31(2), pp. 309-319

Zadeh, L.A., 1988. Fuzzy Logic. Computer, Volume 21(4), pp. 83-93

Zavadskas, E., Zakarevicius, A., Antucheviciene, J., 2006. Evaluation of Ranking Accuracy in Multi-criteria Decisions. Informatica, Volume 17(4), pp. 601-618

Zhao, Z., Liu, L., Liu, F., 2008. Airport Internal Safety Risk Assessment using Fuzzy Hierarchy Process Approach. In: Proceeding of International Symposium on Computational Intelligence and Design 